\title{
Contested Tender Offers: An Estimate of the Hazard Function
}

\author{
Sanjiv JAGGIA \\ Department of Economics, Suffolk University, Boston, MA 02108 \\ Satish THosar \\ Department of Finance and Accounting, University of Massachusetts, Boston, MA 02125
}

\begin{abstract}
In this article we estimate the hazard function (takeover probabilities) for firms that are targets in unsolicited tender offers. The data support a Weibull-gamma specification and imply a hazard rate that increases sharply in the initial period following the bid announcement, after which it declines steadily. In explaining the hazard, we find that the initial bid premium has no explanatory power, but the onset of an auction and the proportion of institutional ownership in the target firm significantly enhance the hazard. Legal and financial restructuring actions by target management are effective in reducing the hazard, thereby prolonging the contest.
\end{abstract}

KEY WORDS: Duration model; Graphical and moment restriction test; Management resistance; Takeover probability.

A problem common to many fields of inquiry concerns the length of time that an individual spends in a particular state and the probability, given this length of time (or duration), of his exiting that state. Duration models are used to explain how individual characteristics affect this duration and how the elapsed duration affects the chances of exiting that state. Such models have long been used in the engineering and medical fields; more recently they have been used in labor economics to analyze unemployment and strike durations [see Lawless (1982) and Kiefer (1988) for comprehensive surveys].

In this article, we apply duration models to the analysis of the length of time between the initiation of an unsolicited bid for a firm and the resolution of the resulting takeover contest. The duration of the contest is of importance to several interested parties. For example, the Securities and Exchange Commission (S.E.C.) is required, under the Williams Act, to draft and enforce rules relating to notice and waiting periods in tender offers and the withdrawal time allowed to stockholders. The legislative intent is to have the S.E.C. design rules that enable target-firm stockholders to make informed decisions when confronted with a tender offer.

Other interested parties include bidders who would like to end the contest as quickly as possible to exploit whatever synergies they have spotted and to deter third parties from entering with higher bids. Target management, on the other hand, would prefer to delay the process so as to enhance their action set, possibly through the erection of barriers to protect their own jobs/perquisites (managerial entrenchment), or to generate an auction so that stockholders get the best possible deal. Furthermore, risk arbitrageurs are interested in cashing out their positions at the optimal point in the takeover contest so as to maximize returns. Consequently, the duration of the takeover contest is im- portant from several perspectives. Previous empirical work has ignored this important time dimension in takeover contests.

We use three parametric models to estimate the hazard function conditional on defensive actions by management and various target-firm characteristics. The shape parameter(s) of the hazard function determine(s) how the instantaneous probability that a target firm will be taken over changes over the duration of the contest. The scale parameters, influenced by the regressors, indicate how this probability differs across firms at any given point in time. Furthermore, MacKinnon (1992) stressed that, because parameter estimates are sensitive to the choice of the model, highly misleading inferences may be reached if the underlying model specification is incorrect. Consequently, we implement several model-specification tests and find that our data support a Weibull-gamma specification.

The estimated hazard increases sharply in the initial period following the bid announcement, after which it declines steadily. Of the defensive action measures, legal defense and financial restructuring are significant. We find that both variables reduce the hazard and are, therefore, instrumental in prolonging the contest. As regards target-firm characteristics, the onset of an auction and the proportion of institutional ownership enhance the hazard. The initial bid premium and regulatory intervention do not appear to affect the hazard.

The rest of the article is organized as follows: In Section 1 , we outline the estimation and specification testing procedures involving duration models. In Section 2, we describe the data-collection procedure and sample characteristics. In Section 3, we describe our model search and present diagnostic test results. In Section 4, we present the parameter estimates and interpretation of the results. In Section 5, we make our concluding comments. 


\section{METHODOLOGY}

In duration models, it is customary to specify the parametric form of the model in terms of its hazard function rather than the probability density function (pdf) even though the two functions are mathematically equivalent. The hazard function $h(t)=f(t) / S(t)$, where $f(t)$ is the pdf and $S(t)=P(T>t)$ is the survivor function of $T$, where $T$ represents the duration of the contest. The survivor function evaluated at time $t$ represents the probability that the firm will not be taken over (will survive) until time $t$. Analogously, the hazard specifies the instantaneous probability that the target firm will be taken over at time $t+\delta t$, for a very small $\delta$, given that it has survived up to time $t$. Duration dependence exists when $(d / d t) h(t) \neq 0$, implying that the probability of a takeover is affected by the length of time spent in the contest. Dependence is positive when $(d / d t) h(t)>0$ and negative when $(d / d t) h(t)<0$.

For parametric estimation of duration models, one has to specify the a priori functional form of the hazard function. Duration models often employ the Weibull distribution as a first pass, a convention we follow in this study. The hazard function of the Weibull distribution conditional on the regressors $X$ is

$$
h(t ; X)=\mu \alpha t^{\alpha-1},
$$

where the scale parameter $\mu$ is typically taken $\operatorname{as} \exp (X \beta)$ to ensure the nonnegativity of the hazard function. The shape parameter, $\alpha$, allows for positive $(\alpha>1)$, negative $(\alpha<1)$, or the absence $(\alpha=1)$ of duration dependence. The Weibull model, however, may be restrictive because it only allows for monotonically increasing or decreasing hazard functions. For instance, it does not allow for a takeover probability that increases with time initially but falls thereafter. The survivor function of a Weibull model is

$$
S(t ; X)=\exp \left(-\mu t^{\alpha}\right)
$$

A characteristic feature of duration models is that data on durations are seldom complete. It is common for some observations to be right censored because the event of interest has not taken place by the end of the data-acquisition period. In our sample, we follow each takeover contest for a period of 52 weeks. If at this point target firms have still not been taken over, they are classified as remaining independent, thereby representing right-censored observations. Our raw data, for $i=1, \ldots, N$, consist of durations, $t_{i}$, regressors, $X_{i}$, and indicator variable, $C_{i}$, where $C_{i}=1$ if the firm is taken over, 0 if it remains independent (censored).

The following log-likelihood function incorporates complete as well as censored observations, where a right-censored spell contributes a probability $\operatorname{Pr}(T>t)=S(t)$ rather than a density to the function:

$$
\mathcal{L}=\sum_{i=1}^{N}\left[C_{i} \ln \left(f\left(t_{i} ; X_{i}\right)\right)+\left(1-C_{i}\right) \ln \left(S\left(t_{i} ; X_{i}\right)\right)\right] .
$$

If the model is incorrectly specified, however, the estimates obtained by maximizing any likelihood function may lead to spurious inferences (MacKinnon 1992). It is, therefore, crucial to test the validity of the given parametric model before any meaningful inferences can be made.

Unlike the case of linear regression models, there is no natural or automatic way of defining a residual that can be used for testing duration models. Diagnostic tests in duration models are generally based on the following transformation:

$$
\epsilon(t)=-\ln (S(t ; X)) .
$$

Under the null hypothesis of no model misspecification, $\epsilon$ has a unit exponential distribution with

$$
S(\epsilon)=\exp (-\epsilon) \text { and } E\left(\epsilon^{j}\right)=j ! .
$$

For a Weibull model, $\epsilon(t)=\mu t^{\alpha}$. The parameters are replaced by their maximum likelihood estimates to obtain generalized residuals, $\hat{\epsilon}$, for model evaluation (Lancaster 1985).

The property of $\epsilon$, given by (1.5), is used for specification testing in duration models. An informal graphical test consists of plotting $-\ln (\hat{S}(\hat{\epsilon}))$ against $\hat{\epsilon}$, where $S(\hat{\epsilon})$ is the product-limit estimate of $\hat{\epsilon}$. If the model is correctly specified, the scatterplot clusters around a $45^{\circ}$ line through the origin (see Kiefer 1988; Lawless 1982). This test, which works for censored data as well, is based on the visual inspection of departures from the $45^{\circ}$ line.

Generalized residuals are also used for more formal tests. The conditional moment restriction tests based on $E\left(\epsilon^{j}\right)=j$ ! can easily be implemented using the Tauchen (1985) and Newey (1985) framework. For a Weibull model, a test of second-moment restriction, $E\left(\epsilon^{2}\right)=2$, has traditionally been interpreted as a test for neglected heterogeneity, caused primarily by the omission of relevant regressors (see Kiefer 1988; Lancaster 1985). Jaggia (1991) showed that the outcome of this test can also be influenced by other types of misspecifications. Therefore, we interpret this test as a general misspecification ("something is wrong") test rather than a test for heterogeneity per se.

Given that some of our observations are right censored, the preceding residuals have to be suitably adjusted. In our sample, the observed duration is $t=\min [T, L]$, implying that an observation is complete only if it is less than the censoring time of $L=52$ weeks. Note that $\epsilon(t)$ no longer has a unit exponential distribution when data are censored. The memoryless property of a unit exponential distribution of $\epsilon(T)$, however, is used to derive the following result:

$$
E(\epsilon(T) \mid T>L)=\epsilon(L)+E(\epsilon(T))=\epsilon(L)+1 .
$$

Therefore, the residuals are redefined as

$$
\begin{aligned}
\hat{e}(t) & =\hat{\epsilon}(t) & & \text { if uncensored } \\
& =\hat{\epsilon}(t)+1 & & \text { if censored. }
\end{aligned}
$$

Even though the modified generalized errors, $e(t)$, do not have a unit exponential distribution, they still have a unit mean with variance $=\pi^{*}$, where $\pi^{*}$ is the expected probability of censoring. Lancaster and Chesher (1985) provided a test procedure that examines whether $s^{2}=\Sigma\left(C_{i} / N\right)$, where $s^{2}$ is the sample variance of $\hat{e}(t)$ and $\Sigma\left(C_{i} / N\right)$ is the sample proportion of censored observations. The test statistic used to check the second-moment restriction of $e(t)$ has an easily 
implementable form. An ordinary least squares regression is run in which the left-side variable is unity and the right side consists of $\left(\hat{e}_{i}-1\right)^{2}-C_{i}$ and all $\partial \mathcal{L}_{i} / \partial \Theta_{j}$, where $\Theta_{j}(j=$ $1, \ldots, k)$ represent the parameters of the model. The test is computed as the sample size, $N$, multiplied by the uncentered $R^{2}$ and has an asymptotic $\chi^{2}(1)$ distribution under the null.

\section{DATA AND SAMPLE CHARACTERISTICS}

The sample comprises firms listed on the New York or American stock exchanges that were targets of tender offers during the period 1978-1985. The year 1978 is a natural starting point for the analysis because the rules governing the Williams Act were revised in late 1977. The target firm and Schedule 14D-1 filing data were identified from the S.E.C. News Digest, which is published on each working day. A Schedule 14D-1 form has to be filed by the bidder with the S.E.C. prior to the commencement of the tender offer. The public announcement date for the tender offer was identified from the Wall Street Journal Index (WSJI). This date typically coincides with the Schedule 14D-1 filing date but in some cases precedes it. The starting date for the contest is the Schedule 14D-1 filing date or the date of the public announcement according to the WSJI, whichever is earlier. Furthermore, the WSII was scanned beyond the starting date to record the occurrence/dates of any of the following events:
A. Intervening Events
1. One or more forms of target management resistance
2. Interventions by regulatory authorities
3. Competing bids by third parties
4. Enhanced bids by original bidder
B. Final Outcomes
1. Target firm gets taken over
2. Target firm remains independent

The ending date for the contest is recorded based on the WSJ article summary indicating that the requisite number of shares were tendered. If forward scanning in the WSJI for 52 weeks did not result in recording a definitive outcome, the target firm was classified as remaining independent. This is an example of right censoring explained in Section 1.

All 14D-1 filings do not necessarily constitute contests for corporate control. In some cases the tender offer might be for less than a controlling interest or target management may remain passive or even acquiesce in the takeover bid. Such tender offers are not included in our data set because our study focuses only on contests for corporate control. Our sample consists of 152 target firms of which 25 durations are censored. Table 1 provides a frequency distribution of contest durations. Note that, of the uncensored durations, most firms were taken over in the 5-10 week interval.

The data set also includes information on the following explanatory variables that are employed in the analysis:

\section{Target Management Actions}

1. Legal defense takes value 1 if target management responds with a lawsuit or proposes an antitakeover charter amendment, 0 otherwise. The choice of this variable is
Table 1. Sample Duration Frequencies $(N=152)$

\begin{tabular}{cc}
\hline \hline $\begin{array}{l}\text { Duration times }(t) \\
\text { in weeks }\end{array}$ & $\begin{array}{c}\text { No. of firms } \\
\text { taken over }\end{array}$ \\
\hline $0<t \leq 5$ & 16 \\
$5<t \leq 10$ & 59 \\
$10<t \leq 15$ & 25 \\
$15<t \leq 20$ & 13 \\
$20<t \leq 25$ & 6 \\
$25<t \leq 30$ & 3 \\
$30<t \leq 35$ & 1 \\
$35<t \leq 40$ & 3 \\
$40<t \leq 45$ & 1 \\
$45<t \leq 50$ & 0 \\
$t>50$ & 25 \\
\hline
\end{tabular}

due to the Jarrell (1985) study. Jarrell concluded that target managements appear to take a value-maximizing gamble by engaging in legal defensive activity. If the filing of a lawsuit, or the threat to do so, creates a delay in the tender-offer process, this will have a negative influence on the hazard.

2. Real restructuring takes value 1 if target management proposes some change in the asset structure, 0 otherwise.

3. Financial restructuring takes value 1 if target management proposes some change in the ownership structure, 0 otherwise.

The two variables just cited were originally characterized by the Dann and DeAngelo (1988) study. This study strongly indicted target management for entrenchment behavior. If this type of defensive activity is credible, it is expected to exert a negative effect on the hazard.

\section{Firm-Specific Characteristics}

4. Bid premium percentage represents the percentage excess of the first hostile-bid price over the market price of the firm's stock 14 working days prior to the tender-offer announcement. The idea is to select a time frame that allows for information leakage prior to the public announcement; the precedent for 14 days was set by Walkling (1985), who employed a logit model to predict takeover success. We expect this variable to positively influence the hazard. Our reasoning is that a high initial bid leaves target management less room to maneuver.

5. Institutional holdings percentage serves as a proxy for stockholder independence [or as a converse to insider holdings; see Brickley, Lease, and Smith (1988)]. Defensive actions by management may be more closely monitored in firms with a higher percentage of institutional owners. The percentage of institutional holdings to total outstanding stock was ascertained from the Standard \& Poor's Stockholder Guide and is expected to positively influence the hazard.

6. Intervention by regulatory authorities takes value 1 if either the Federal Trade Commission or the Justice Department intervenes by way of requesting additional information or mounting a court challenge to the tender offer, 0 otherwise. We expect regulatory intervention to reduce the hazard.

7. Auction takes value 1 if the target firm receives at least one enhanced bid from the original bidder or a competing bid from a third-party bidder, 0 otherwise. The onset of an 
Table 2. Sample Characteristics $(N=152)$

\begin{tabular}{lrclc}
\hline \hline Variables & Mean & Std. dev. & Min. & Max. \\
\hline Duration in weeks $(t)$ & 18.086 & 16.65 & 2.85 & 52 \\
Censoring variable $(C)$ & .835 & .37 & 0 & 1 \\
Legal defense & .480 & .50 & 0 & 1 \\
Real restructuring & .190 & .39 & 0 & 1 \\
Financial restructuring & .177 & .38 & 0 & 1 \\
Initial bid premium & 1.303 & .18 & .88 & 1.95 \\
Institutional holdings & .254 & .18 & 0 & .90 \\
Regulation & .250 & .43 & 0 & 1 \\
Auction & .868 & .33 & 0 & 1 \\
\hline
\end{tabular}

auction process is expected to exert a positive influence on the hazard.

In Table 2, we present descriptive statistics of all the variables used in the analysis.

\section{MODEL FITTING AND SPECIFICATION TESTS}

In this section we report results of specification tests, described in Section 1, sequentially carried out on three models. Maxımum likelihood estimates of all models are obtained using the MAXLIK module of the GAUSS programming language. The model is first estimated using the Weibull model, and the corresponding graph used for evaluating this model is given in Figure 1. Note that the focus should be on departures from the $45^{\circ}$ line for smaller values of the generalized residuals. In general, as Kiefer (1988) reported, the accuracy of the product-limit estimator of the survivor function is better for shorter durations because inferences about longer durations are based on fewer observations. Consequently, the top right part of the graph is of negligible importance. The graphical test of the Weibull model suggests considerable departures from the $45^{\circ}$ line for the relevant, lower left portion

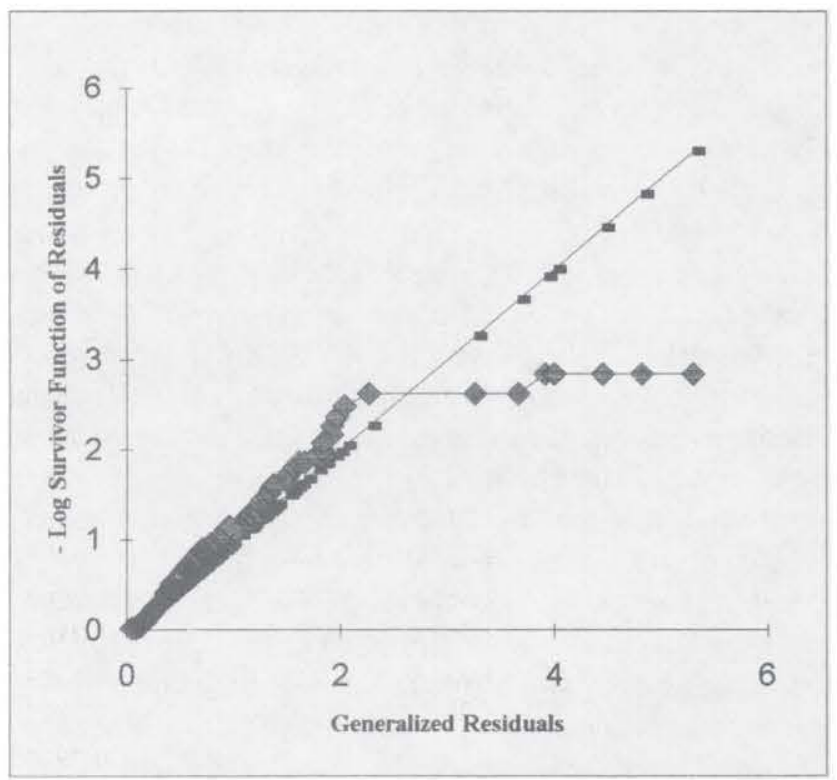

Figure 1. Graphical Test for Weibull Specification. Departures from the straight line, especially at the lower left portion of the graph, imply misspecification.
Table 3. Test Statistics Under Alternative Model Specifications

\begin{tabular}{lcrl}
\hline \hline Null & Alternative & \multicolumn{2}{c}{ Test Statistic } \\
\hline \multicolumn{4}{c}{ Second moment restriction test } \\
Weibull & Not Weibull & 26.22 & $(p=.00)$ \\
Log-logistic & Not log-logistic & 5.54 & $(p=.02)$ \\
Weibull-gamma & Not Weibull-gamma & 2.22 & $(p=.14)$ \\
& Likelihood ratio test \\
Weibull & Weibull-gamma & & \\
Log-logistic & Weibull-gamma & 21.97 & $(p=.00)$ \\
& & &
\end{tabular}

NOTE: The $p$ in parentheses refers to the $p$ value of the test statistics, which are all dis tributed $\chi^{2}(1)$ under the null.

of the graph (see Fig. 1). Furthermore, the formal test for the second-moment restriction clearly indicates misspecification (see Table 3).

The Weibull model is clearly inappropriate, which could be simply because the Weibull distribution is restrictive and allows only for monotonic hazard rates. For instance, the $\alpha$ estimate of the Weibull model is 1.23 , which implies a hazard function that continuously increases over time. This implication is counterintuitive because the probability of takeover ought to decline beyond some reasonable point in time. Some takeover bids will eventually fail either due to antitrust considerations or because, given enough time, a determined target management will implement defensive measures that are not in the bidder's interest to overcome. The intuition is further supported by the fact that most firms in our sample either were taken over within a relatively short period of time or remained independent (see Table 1).

To search for a more appropriate model, $\mu(X)$ can be written as

$$
\mu(X)=\exp (X \beta+U)=V \exp (X \beta),
$$

where $V$ can be thought of as a proxy for omitted regressors or, more generally, some intrinsic randomness in the model. The survivor function for a Weibull model is

$$
S(t ; X, V)=\exp \left(-V \exp (X \beta) t^{\alpha}\right) .
$$

Because $V$ is not observable, the survivor function conditional only on $X$ is

$$
S(t ; X)=\int \exp \left(-V \exp (X \beta) t^{\alpha}\right) p(V) d V .
$$

Once the mixing distribution $p(V)$ is specified, $S(t ; X)$ is computed to estimate the parameters of the model.

Several authors (Lancaster 1979; Vaupel, Manton, and Stallard 1979; among others) used the gamma distribution as a convenient mixing distribution. If $p(V)$ represents the density function of a gamma variate with a unit mean and variance $=\sigma^{2}$, then

$$
S(t ; X)=\left[1+\sigma^{2} \exp (X \beta) t^{\alpha}\right]^{-1 / \sigma^{2}} .
$$

The corresponding hazard and the density functions are derived similarly. Note that the preceding function (3.4) collapses to the Weibull survivor function (1.2) for $\sigma^{2} \rightarrow 0$. Once again it is stressed that the mixing distribution is used not only to compensate for omitted regressors but also to correct for an overly restrictive Weibull hazard function. More- 


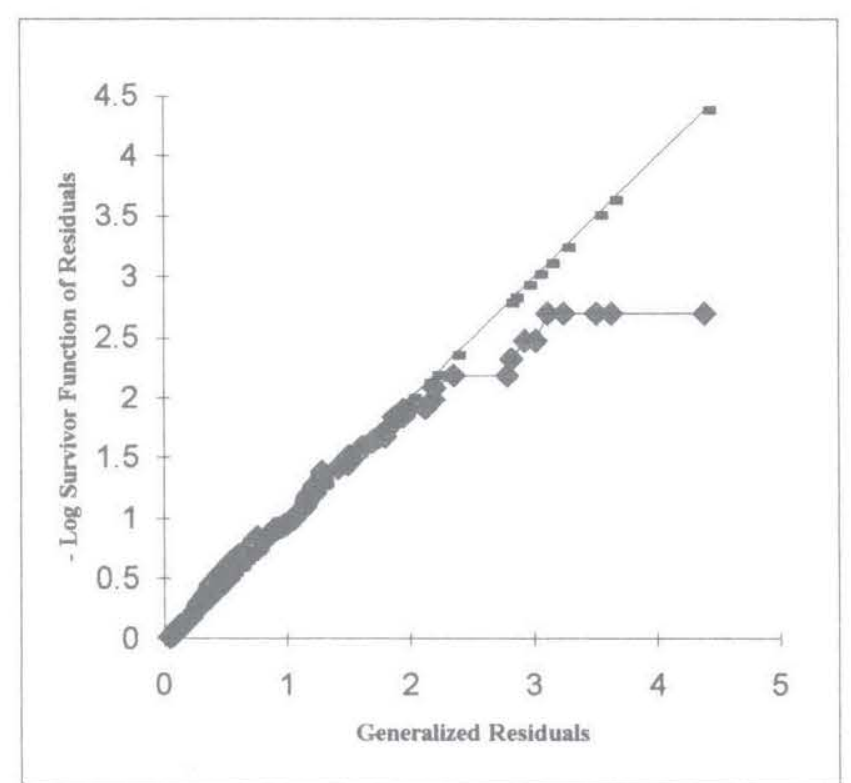

Figure 2. Graphical Test for Log-Logistic Specification. Departures from the straight line, especially at the lower left portion of the graph, imply misspecification.

over, a Weibull-gamma model specializes to a log-logistic model $\left(\sigma^{2}=1\right)$. Such a model may be appropriate for the problem that we address because the hazard function of a $\log$-logistic distribution declines for sufficiently large $T$. One would intuitively expect firms to be less susceptible to being taken over if they can successfully ward off the raider for a reasonably long period of time.

Graphical and second-moment restriction tests are based on the generalized errors, $\epsilon$, where

$$
\epsilon=\ln \left(1+\exp (X \beta) t^{\alpha}\right)
$$

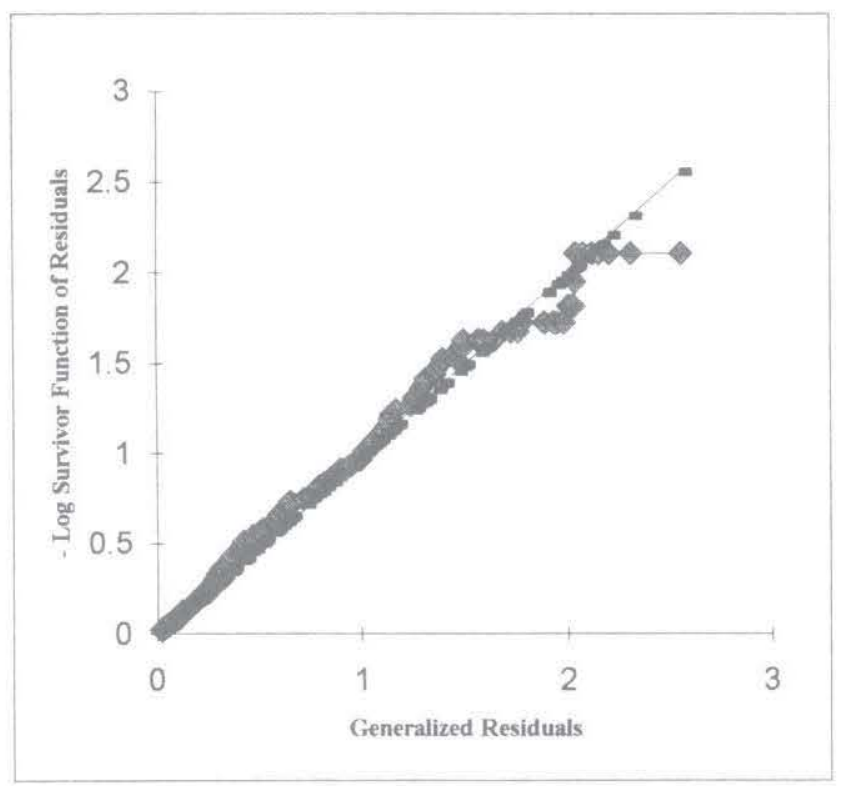

Figure 3. Graphical Test for Weibull-Gamma Specification. Departures from the straight line, especially at the lower left portion of the graph, imply misspecification. for the log-logistic model and

$$
\epsilon=\left(1 / \sigma^{2}\right) \ln \left(1+\sigma^{2} \exp (X \beta) t^{\alpha}\right)
$$

for the Weibull-gamma model. The corresponding residuals, obtained by evaluating the preceding equations at their maximum likelihood estimates, are used to implement the tests described in Section 1. Graphical tests conducted on both the log-logistic and the Weibull-gamma models indicate a marked improvement over the Weibull model (see the relevant portions of Figs. 2 and 3). The second-moment restriction test supports the Weibull-gamma model, however, whereas the log-logistic model is rejected at a 5\% significance level (see Table 3). The likelihood ratio tests, computed by taking twice the difference between the maximized log-likelihood values of the null and the alternative models, are also computed. The results for the Weibull and log-logistic models in which the alternative specification is Weibull-gamma corroborate the finding that the Weibull-gamma model is appropriate (see Table 3).

\section{ESTIMATION RESULTS}

The results of the three estimated models are presented in Table 4. We observe that the legal defense, financial restructuring, institutional holdings, and auction variables are statistically significant at a $10 \%$ level (or better), with the coefficient signs being in the hypothesized direction, in all the models we estimate. The basic difference between the three model specifications seems to be in terms of the behavior of the hazard over time. As discussed in Section 3, the Weibull-gamma specification provides the best fit.

Table 4. Hazard-Function Estimates Under Alternative Model Specifications

\begin{tabular}{lccc}
\hline \hline Variable & Weibull & Log-logistic & Weibull-gamma \\
\hline Constant & -4.8368 & -7.4899 & -14.4614 \\
& $(.7908)$ & $(1.2881)$ & $(3.2632)$ \\
Legal defense & -.3844 & -.8192 & -1.3734 \\
& $(.1973)$ & $(.3128)$ & $(.7160)$ \\
Real restructuring & -.4285 & .1302 & 1.0643 \\
& $(.2493)$ & $(.4175)$ & $(.8659)$ \\
Financial restructuring & -1.3655 & -1.7959 & -1.7136 \\
& $(.3231)$ & $(.4976)$ & $(.9291)$ \\
Bid premium & .0778 & .4994 & .0175 \\
& $(.5080)$ & $(.7929)$ & $(1.6663)$ \\
Institutional holdings & 1.2146 & 1.5555 & 3.0437 \\
& $(.5261)$ & $(.8336)$ & $(1.7108)$ \\
Regulation & .0133 & -.1258 & -.3839 \\
& $(.2117)$ & $(.3329)$ & $(.8193)$ \\
Auction & 1.3664 & 2.0503 & 2.2887 \\
& $(.3542)$ & $(.5393)$ & $(1.3169)$ \\
$\alpha$ & 1.2316 & 2.0815 & 6.3359 \\
& $(.0834)$ & $(.1540)$ & $(1.3795)$ \\
$\sigma^{2}$ & & & 6.7926 \\
& & & $(1.8875)$ \\
Log-likelihood value & -197.092 & -181.793 & -171.105 \\
\hline
\end{tabular}

NOTE: Standard errors are in parentheses; $\alpha$ and $\sigma^{2}$ are the shape parameters of the hazard models. 


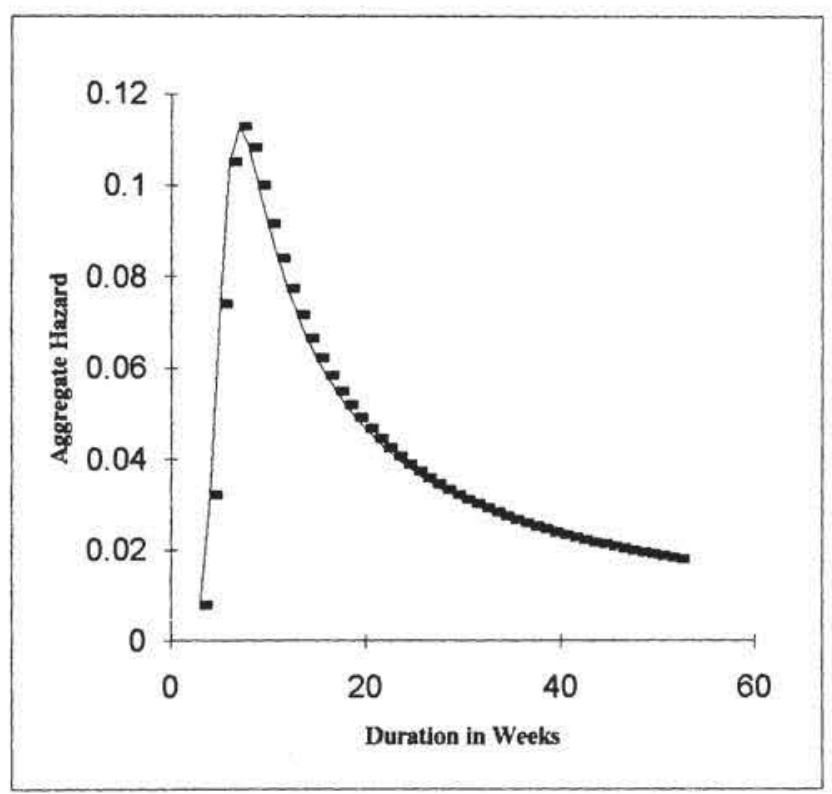

Figure 4. Simulated Weibull-Gamma Hazard Function. The hazard function for durations ranging from 1 to 52 weeks is derived using parameter estimates and regressors evaluated at mean values.

The shape parameters, $\alpha$ and $\sigma^{2}$, for the estimated Weibullgamma model are both found to be statistically significant at any reasonable level, indicating that the data exhibit duration dependence. Note that $\sigma^{2}$ is significantly different from 0 as well as 1 , confirming that the alternate models, Weibull and log-logistic, are both inappropriate. The parameter estimates of the Weibull-gamma model are used to simulate the aggregate hazard function (see Fig. 4) evaluated at the mean value of the regressors. The firms are at no risk during the first 20 days due to the current notice-period requirements established by the S.E.C. Note that our data reflect this legal requirement because the simulated aggregate hazard in Figure 4 is effectively 0 for weeks 1 and 2 . Thereafter, the hazard rises sharply, peaks at about the seventh week, and then declines steadily. The steep rise in the hazard function beyond the third week can perhaps be attributed to the informational free-rider problem discussed by Easterbrook and Fischel (1981). A certain amount of search cost has to be incurred, to identify undervalued firms (targets), by the initial bidder. Since the takeover bid is required by S.E.C. regulations to be publicly announced, the target firm becomes vulnerable to all potential bidders, not just the initial bidder. The data, however, appear to suggest that, if target management can withstand the early weeks of the contest, the risk of being taken over declines over time. Professional managers often do not have a large ownership stake in the firm they manage and hence the contest is typically waged using corporate funds. Conversely, the bidder, using external resources, clearly has to take time-value considerations into account and therefore is at a disadvantage if the contest is prolonged.

Besides bidders and targets, the nature of the hazard function is likely to be of interest to other constituencies as well. Regulators from the S.E.C. are responsible for drafting and enforcing rules relating to notice and waiting periods in tender offers, the withdrawal time allowed to stockholders and so forth. These rules are designed, within the framework of the Williams Act, to permit target-firm stockholders to make informed decisions when confronted with a tender offer. For instance two of the salient rules currently governing tender offers are (1) the tender offer must remain open for at least 20 business days from commencement of the tender offer and for 10 business days from the date the bidder first gives notice of increase in the offered consideration, and (2) any person who has deposited securities may withdraw them any time until the expiration of 15 business days from the date of commencement of the tender offer and in the event of a competing tender offer within 10 business days following the date of commencement of the competing offer. In our opinion, it may be helpful to the S.E.C. to use a hazard-model approach in framing the appropriate rules.

Furthermore, risk arbitrageurs are interested in cashing out their positions at the optimal point in the takeover contest so as to maximize returns. It is likely that target-firm stock price will be highest when the instantaneous takeover probability (or hazard) is at a maximum. In our sample, the optimal cash-out point would have been seven weeks into the contest, on average. Investors could estimate an individual hazard function once a contest gets underway and make their timing decisions accordingly.

We turn next to a discussion of the variables that influence the relative probabilities of firms getting taken over at a given point in time. Of the variables that capture post-bid defensive actions by management, the legal defense and financial restructuring (proposed changes in ownership structure either via a self-tender or a new security issue) variables are both significant at $10 \%$ levels. Because the coefficients on these variables are negative, they both mitigate the hazard and prolong the contest. The latter finding is broadly supportive of those reported by Dann and DeAngelo (1988), who reported significantly negative abnormal returns to target-firm stockholders around managerial resistance announcements. This has been interpreted in the literature as the market's downward revision of the probability that the takeover will go through. The real restructuring actions variable (proposed purchases or sales of assets) is found to be insignificant, however.

The bid-premium percentage variable is insignificant, suggesting that the initial bid premium has no influence on the contest duration. Walkling (1985), however, using a logit model, reported that the bid premium does have a significant influence on takeover probability. Although we use Walkling's approach in measuring the bid-premium percentage, our approach is not directly comparable to the Walkling study for several reasons. First, the logit methodology ignores the time element in takeover contests. Furthermore, Walkling considered both contested and uncontested tender offers, but we only study the former. Finally, we do not include any bidder characteristics (such as percentage of bidder-controlled shares or solicitation fees) in our set of regressors, due primarily to data limitations, but instead focus on various forms of target-management resistance. Note that 
prior studies (cited by Walkling) also found that the initial bid premium does not play a significant role in the outcome of the contest.

The insignificance of the bid premium is perhaps due to the onset of an auction, which swamps the impact of the initial bid. We find that the auction variable is significant at a $10 \%$ level. Because the auction variable has a positive effect on the hazard, the duration of the contest is lower for a firm that receives multiple bids. Clearly, once an auction process gets underway, the offer price is bid up and target management feels stockholder pressure to accept the highest bid. In general, if the takeover goes through, incumbent management is replaced. It is important to note, however, that in some instances target management seeks an auction by pursuing a "white knight" strategy. In this context, from management's perspective the hazard is a dilution of, rather than a loss of, control.

The coefficient on the institutional holdings percentage variable is positive and significant at the $10 \%$ level. This conforms to the view that institutional holders generally exercise a monitoring influence on incumbent management which arguably translates into pressure to accept an attractive tender offer. Surprisingly, regulatory intervention does not appear to influence the hazard. Normally one would expect that an antitrust objection by the Justice Department would reduce the chances of the takeover going through. A possible explanation for this lies in the fact that most of the contests in our sample occurred in the 1980s, a period during which the Justice Department was widely perceived as adopting a laissez-faire attitude to corporate restructuring activity.

\section{CONCLUSION}

Previous empirical studies in the area of corporate control have generally focused on measuring stockholder wealth effects for the firms involved; see Jensen and Warner (1988) for a summary of the evidence. In this article, we take a different approach. We employ duration models to estimate the hazard function for firms that are targets of hostiletakeover bids. Our model search, based on graphical as well as formal specification tests, suggests that the Weibullgamma model is appropriate for our application.

The estimated hazard function for the chosen model shows that the probability of takeover increases sharply following the initial bid, peaks at seven weeks, and tails off thereafter. This could have policy implications with respect to the time frames adopted by the S.E.C. for notice/waiting periods for tender offers. This result could also be of interest to risk arbitrageurs in terms of their investment timing decisions.

We also study the influence of various defensive actions by management and target-firm characteristics on the hazard.
We find that legal defense and financial restructuring are effective in reducing the hazard, thus prolonging the contest. As regards target-firm characteristics, the onset of an auction process and the monitoring influence of institutional investors apparently creates pressure on incumbent management to capitulate.

\section{ACKNOWLEDGMENTS}

We thank Arnaud Boot, Priscilla Butt-Jaggia, William T. Moore, Pravin K. Trivedi, David G. Tuerck, James Wansley, two anonymous referees, and an associate editor for useful comments. Any remaining errors are our own.

[Received May 1992. Revised April 1994.]

\section{REFERENCES}

Brickley, J. A., Lease, R. C., and Smith, C. W. (1988), "Ownership Structure and Voting on Antitakeover Amendments," Journal of Financial Economics, 20, 267-291.

Dann, L. Y., and DeAngelo, H. (1988), "Corporate Financial Policy and Corporate Control: A Study of Defensive Adjustments in Asset and Ownership Structure," Journal of Financial Economics, 20, 87-127.

Easterbrook, F. H., and Fischel, D. R. (1981), "The Proper Role of a Target's Management in Responding to a Tender Offer," Harvard Law Review, 94, 1161-1204.

Jaggia, S. (1991), "Specification Tests Based on the Heterogeneous Generalized Gamma Model of Duration: With an Application to Kennan's Strike Data," Journal of Applied Econometrics, 6, 169-180.

Jarrell, G. (1985), "The Wealth Effects of Litigation by Targets: Do Interests Diverge in a Merge," Journal of Law and Economics, 28, 151-179.

Jensen, M., and Warner, J. (1988), "The Distribution of Power Among Corporate Managers, Shareholders, and Directors," Journal of Financial Economics, 20, 3-24.

Kiefer, N. M. (1988), "Econometric Duration Data and Hazard Functions," Journal of Economic Literature, 25, 646-679.

Lancaster, T. (1979), "Econometric Methods for the Duration of Unemployment," Econometrica, 47, 939-956.

- (1985), "Generalized Residuals and Heterogeneous Duration Models: With Applications to the Weibull Model," Journal of Econometrics, 28, 155-169.

Lancaster, T., and Chesher, A. (1985), "Residual Analysis for Censored Duration Data," Economics Letters, 18, 35-38.

Lawless, J. F. (1982), Statistical Models and Methods for Lifetime Data, New York: John Wiley.

MacKinnon, J. G. (1992), "Model Specification Tests and Artificial Regressions," Journal of Economic Literature, 30, 102-146.

Newey, W. K. (1985), "Maximum Likelihood Specification Testing and Conditional Moment Tests," Econometrica, 53, 1047-1070.

Tauchen, G. E. (1985), "Diagnostic Testing and Evaluation of Maximum Likelihood Models," Journal of Econometrics, 30, 415-443.

Vaupel, J. W., Manton, K. G., and Stallard, E. (1979), "The Impact of Heterogeneity in Individual Frailty on the Dynamics of Mortality," Demography, $16,439-454$.

Walkling, R. A. (1985), "Predicting Tender Success: A Logistic Analysis," Journal of Financial and Quantitative Analysis, 20, 461-478. 